Article

\title{
Effects of Au nanoparticle size and metal-support interaction on plasmon-induced photocatalytic water oxidation
}

\author{
Shengyang Wang a,b, Bin Zeng a,b, Can Li a,* \\ a State Key Laboratory of Catalysis, Dalian National Laboratory for Clean Energy, and the Collaborative Innovation Center of Chemistry for Energy Mate- \\ rials (iChEM), Dalian Institute of Chemical Physics, Chinese Academy of Sciences, Dalian 116023, Liaoning, China \\ b University of Chinese Academy of Sciences, Beijing 100049, China
}

\section{A R T I C L E I N F}

\section{Article history:}

Received 27 December 2017

Accepted 29 April 2018

Published 5 July 2018

\section{Keywords:}

$\mathrm{Au} / \mathrm{TiO}_{2}$

Water oxidation

Plasmonic photocatalysis

Size effect

Metal-semiconductor interaction

\begin{abstract}
A B S T R A C T
Plasmonic photocatalysis with tunable light absorption has aroused significant attention in solar-to-chemical energy conversion. However, the energy conversion efficiency of plasmonic photocatalysts is impeded by ineffective charge separation and the lack of highly active sites for redox reactions. In this work, the $\mathrm{Au}$ nanoparticle size and $\mathrm{Au}-\mathrm{TiO}_{2}$ interaction of the $\mathrm{Au} / \mathrm{TiO}_{2}$ plasmonic photocatalyst were adjusted simultaneously using a post-calcination treatment. The visible-light-induced water oxidation activity exhibited a volcano-like relationship with the calcination temperature; the treated photocatalyst at $600{ }^{\circ} \mathrm{C}$ manifested the highest activity. Characterization with UV-visible spectra, XRD, SEM, and XPS revealed that the effect of the Au nanoparticle size and $\mathrm{Au}-\mathrm{TiO}_{2}$ interaction were both responsible for the increase in plasmon-induced water oxidation activity.
\end{abstract}

(C) 2018, Dalian Institute of Chemical Physics, Chinese Academy of Sciences. Published by Elsevier B.V. All rights reserved.

\section{Introduction}

The demand for sustainable energy has aroused worldwide interest in the conversions of solar energy to chemical fuels. Photocatalysis using sunlight is regarded as one of the technologies with the highest potential to alleviate energy and environmental issues [1-3]. Plasmonic photocatalysis has recently received tremendous attention as an emerging method for the enhancement of the photocatalytic performance of semiconductor-based photocatalysts based on the localized surface plasmon resonance (LSPR) effect [4-6].

LSPR is refers to the collective oscillations of free electrons confined to the surface of metal nanostructures are in resonance with upon excitation with external fields (light for instance) [7]. These metallic nanostructures can substantially concentrate incident light into a nanoscale volume and can then generate hot carriers or build electromagnetic fields to assist the separation of hot carriers [8]. Since the properties of LSPR are sensitive to the size and shape of the plasmonic nanoparticles (NPs) as well as their environment, the optical absorption of plasmonic NPs can easily be tuned to match the entire solar light spectrum [9]. What is more, the extremely large absorption cross sections of plasmonic NPs can capture light more efficiently than other optical materials [10]. These potential advantages make plasmonic NPs an ideal candidate for harnessing solar energy [11-14]. Jang et al. [15] have reported that shape-controlled gold NPs on wide bandgap semiconductors can improve water-splitting photoactivity; they found that plasmonic octahedral gold NPs could be maximized near electromagnetic fields. Other plasmon-enhancement strategies

\footnotetext{
* Corresponding author. Tel: +86-411-84379070; Fax: +86-411-84694447; E-mail: canli@dicp.ac.cn

This work was supported by the National Natural Science Foundation of China (21633010), the National Basic Research Program of China (973 program, 2014CB239400), and the Strategic Priority Research Program of the Chinese Academy of Sciences (XDB01020300).

DOI: 10.1016/S1872-2067(18)63094-3 | http://www.sciencedirect.com/science/journal/18722067 | Chin. J. Catal., Vol. 39, No. 7, July 2018
} 
have also been adopted to boost the efficiency of solar energy conversion, these include the use of aluminum or alloy metals to replace the noble metals $[16,17]$.

The electron-hole pairs generated through plasmon energy dissipation can be utilized for chemical reactions on plasmonic photocatalysts in the form of metal/semiconductor nanostructures [18]. Plasmonic sensitization, also known as plasmon-induced charge transfer (PICT), is the mechanism by which the electrons in a metal are transferred to an adjacent semiconductor upon the excitation of the LSPR at the metal/semiconductor interface [19]. The metal-support interface is crucial for the electron-transfer process in this mechanism. The interfacial effect is dependent on several factors including the nature of the metal NPs, the nature of the semiconductor support, and their interaction $[20,21]$. The influence of the metal NPs as cocatalysts has been widely studied in conventional semiconductor photocatalysis by adjusting their size, morphology, and composition [22-25]. However, in plasmonic photocatalysts it is more complex since plasmonic NPs act as both photo-absorbers and catalytic sites. On the other hand, the interplay between the plasmonic metal and large-band-gap semiconductor is important for the overall photocatalytic reactivity. In addition to the influence on charge transfer, the metal-support interface exerts a significant impact on the surface catalytic reactions, this has been widely studied in heterogeneous catalytic science [26-29]. However, the details of the interfacial effect in plasmonic photocatalysts are still unclear.

$\mathrm{Au} / \mathrm{TiO}_{2}$ is the archetypical plasmonic photocatalyst widely used in plasmon-driven photocatalysis [30-35]. In particular, it has been demonstrated that it can initiate a water splitting reaction [36,37]. The effect of the size of Au NPs has been observed in both water reduction and oxidation reactions, but offer different conclusions [32,38]. Recently, the influence of crystallinity and the crystallite size of the $\mathrm{TiO}_{2}$ semiconductor support has also been investigated, indicating various trends for different reactions [39-41]. There is a lack of understanding of how plasmonic reactions depend on the parameters usually involved in catalysis, particularly in oxygen evolution reactions. Photocatalytic water splitting is an ideal clean system for creating hydrogen and oxygen from water using solar energy, among which water oxidation is regarded as a bottleneck because of its sluggish kinetics and high overpotential [42]. In addition, it is still a challenge to take all of the factors into consideration for a single plasmonic photocatalyst in a water oxidation reaction.

Herein, we report on the plasmon-driven photocatalytic water oxidation reaction on preformed $\mathrm{Au} / \mathrm{TiO}_{2}$ photocatalysts with various sizes of $\mathrm{Au} \mathrm{NPs}$ and $\mathrm{Au}-\mathrm{TiO}_{2}$ interactions. We have developed a facile synthetic method for adjusting both the $\mathrm{Au}$ size and metal-support interaction by altering the calcination temperature. The size of the Au NPs can be turned between 3 and $40 \mathrm{~nm}$, and the interaction between $\mathrm{Au}$ and $\mathrm{TiO}_{2}$ enhanced by elevating the calcination temperature. The joint effect of the $\mathrm{Au}$ size and $\mathrm{Au}-\mathrm{TiO}_{2}$ interaction was corroborated through X-ray power diffraction (XRD), scanning electron microscopy (SEM), and X-ray photoelectron spectroscopy (XPS) characterizations. Based on these results, we have demonstrated an op- timized plasmonic photocatalyst for water oxidation with appropriate $\mathrm{Au}$ size and $\mathrm{Au}-\mathrm{TiO}_{2}$ interplay.

\section{Experimental}

\subsection{Material preparation}

Rutile $\mathrm{TiO}_{2}(\sim 25 \mathrm{~nm})$ brought from Aladdin was heated to $900{ }^{\circ} \mathrm{C}$ for $2 \mathrm{~h}$ in air. The calcined samples were used as supports for gold loading. The $\mathrm{Au} / \mathrm{TiO}_{2}$ photocatalyst was prepared with the deposition-precipitation (DP) method using urea as the precipitating base; this permits the gradual and homogeneous addition of hydroxide ions throughout the whole solution. Typically, $3.0 \mathrm{~g}$ of $\mathrm{TiO}_{2}$ was added to $200 \mathrm{~mL}$ of an aqueous solution of $\mathrm{HAuCl}_{4}(0.76 \mathrm{mmol} / \mathrm{L})$ and urea $(0.42$ mol/L). The slurry was thoroughly dispersed by ultrasound and maintained at $85{ }^{\circ} \mathrm{C}$ while vigorously stirred for $4 \mathrm{~h}$. The suspension was separated by centrifugation and washed with deionized water until free of chloride ions. The product was finally dried at $80{ }^{\circ} \mathrm{C}$ overnight. The dried sample was divided into six portions and each portion was calcined in air at a different temperature for $2 \mathrm{~h}$. The obtained samples were denoted as $\mathrm{Au} / \mathrm{TiO}_{2}-T$, where $T(300,400,500,600,700$, and 800$)$ is the heating temperature $\left({ }^{\circ} \mathrm{C}\right)$.

\subsection{Characterization}

The as-prepared samples were characterized by XRD with a Rigaku D/Max-2500/PC powder diffractometer. The sample powder was scanned using $\mathrm{Cu}-K_{\alpha}$ radiation with an operating voltage of $40 \mathrm{kV}$ and current of $200 \mathrm{~mA}$. A scan rate of $5^{\circ} / \mathrm{min}$ was applied to record patterns in the range of $20-80^{\circ}$ at a step size of $0.02^{\circ}$. UV-visible (UV-vis) diffuse reflectance spectra were recorded on a UV-vis spectrophotometer (JASCO V-650) equipped with an integrating sphere. XPS measurements were carried out on a VG ESCALAB MK2 spectrometer with monochromatized $\mathrm{Al}-K_{\alpha}$ excitation, and the $\mathrm{C} 1 s$ peak $(284.6 \mathrm{eV})$ was used as the reference, arising from adventitious carbon. The size and morphology of the particles was examined by field emission scanning electron microscopy (FESEM, Hitachi, S-5500, $40 \mathrm{kV}$ ). The microstructures of the catalysts were further examined using a high-resolution transmission electron microscope (HRTEM, JEM-2100, $200 \mathrm{kV}$ ). The Au content for all of these samples was determined to be approximately $0.8 \mathrm{wt} \%$ by inductively coupled plasma-optical emission spectrometry (ICP-OES).

\subsection{Evaluation of photocatalytic activity}

Photocatalytic $\mathrm{O}_{2}$ evolution was carried out with $50 \mathrm{mg}$ of photocatalyst suspended in $100 \mathrm{~mL}$ water with $5 \mathrm{mM}$ of $\mathrm{Fe}\left(\mathrm{NO}_{3}\right)_{3}$ as a sacrificial reagent. Prior to photoirradiation, the reaction mixture was evacuated to ensure that the air was completely removed. A 300-W Xe arc lamp equipped with an optical cutoff filter (Y48, $\lambda \geq 480 \mathrm{~nm}$ ) was employed as the light source. The corresponding spectra of the light source with the filter are shown in Fig. S1 (Supporting Information, SI). A flow 
of cooling water was used to maintain the reaction mixture at $15^{\circ} \mathrm{C}$. The evolved gases were analyzed by gas chromatography (Agilent; GC-7890A, MS-5A column, TCD, Ar carrier). The apparent quantum yield (AQY) was measured using the same experimental setup as the photocatalytic oxygen evolution with additional band pass filters to obtain monochromatic light at $\lambda$ $=480,520,560,620$, and $640 \mathrm{~nm}$. The oxygen evolution activity under irradiation of 700-800 nm was also tested. The number of photons reaching the reaction solution was measured using a calibrated Si photodiode (LS-100, EKO Instruments Co., LTD.), and the AQY was calculated according to the following equation:

$$
\mathrm{AQY}=\frac{4 \times \text { number of evolved } \mathrm{O}_{2} \text { molecules }}{\text { number of incident photons }} \times 100 \%
$$

\section{Results and discussion}

\subsection{Water oxidation performance of $\mathrm{Au} / \mathrm{TiO}_{2}-\mathrm{T}$}

The typical plasmonic photocatalysts $\mathrm{Au} / \mathrm{TiO}_{2}$ were prepared using the DP method with urea as the precipitation base followed by calcination in air at various temperatures, these samples were denoted as $\mathrm{Au} / \mathrm{TiO}_{2}-T$ (where $T$ represents the calcination temperature). Rutile $\mathrm{TiO}_{2}$ calcined at $900{ }^{\circ} \mathrm{C}$ was used as the support to make sure that the size and crystallization of $\mathrm{TiO}_{2}$ were kept constant during the treatment of the $\mathrm{Au} / \mathrm{TiO}_{2}$ photocatalyst.

$\mathrm{The} \mathrm{Au} / \mathrm{TiO}_{2}$ photocatalysts treated under various temperatures were tested to evaluate the water oxidation half reaction under visible light irradiation $(\lambda>480 \mathrm{~nm})$. Ferric nitrate was used as sacrificial agent to consume the electrons generated from plasmonic $\mathrm{Au}$. The water oxidation activity changed with the calcination temperature, and $\mathrm{Au} / \mathrm{TiO}_{2}-600$ exhibited the highest oxygen evolution activity $(24.2 \mu \mathrm{mol} / \mathrm{h})$ of all of the samples (Fig. 1). The water oxidation reaction is plasmon-driven as bare $\mathrm{TiO}_{2}$ exhibited no photocatalytic activity under the same conditions. For a more objective comparison between the photocatalytic efficiencies of oxygen evolution under different illuminations, the AQY was calculated. As shown in Fig. 1(b), the AQY was in agreement with the subtraction spectrum obtained from the spectra of $\mathrm{Au} / \mathrm{TiO}_{2}-600$, and the highest AQY was approximately $0.32 \%$ at $560 \mathrm{~nm}$. This result indicated that the water oxidation was induced by the surface plasmon resonance (SPR) of Au supported in $\mathrm{TiO}_{2}$. This $\mathrm{AQY}$ is relatively low, but it is comparable to the reported plasmon-induced water oxidation photocatalysts and even comparable to some well-known semiconductor photocatalysts (Table S1). Furthermore, long-time-course water oxidation experiments were carried out under visible light irradiation. As shown in Fig. 1(c), the $\mathrm{O}_{2}$ evolution steadily increased with the irradiation. The deviation from linearity is ascribed to the accumulation of $\mathrm{Fe}^{2+}$ ions and the re-oxidation of $\mathrm{Fe}^{2+}$ may compete with water oxidation. By using a facile calcination method, we succeeded in the preparation of a high activity plasmonic photocatalyst. The calcination temperature is an apparent parameter which may influence optical absorption, support properties, particle size, and metal-semiconductor interactions. It is indispensable to distinguish the role of each factor, which is discussed in detail below.

\subsection{Plasmon absorption and crystal structure effect of $\mathrm{Au} / \mathrm{TiO}_{2}-\mathrm{T}$}

As demonstrated above, the plasmon effect of Au NPs is the main reason for visible-light-induced water oxidation. Thus, the plasmon absorption of photocatalysts is an important parameter for photocatalytic activity. As shown in Fig. 2(a), absorption in the visible region $(450-800 \mathrm{~nm})$ due to the plasmon effect varied with the calcination temperature. The maximum peak gradually shifted to a longer wavelength as the post-calcination temperature increased, indicating that the SPR of supported $\mathrm{Au}$ particles can be shifted by calcination. Meanwhile, the absorption intensity increased with the calcination temperature. The exception for $\mathrm{Au} / \mathrm{TiO}_{2}-800$ is possibly due to the scattering effect of large Au NPs (details are shown below).

There are a few possible reasons for the redshift of the plasmon peak and the enhanced intensity. One is the loading amount of $\mathrm{Au}$. In the preparation process, the annealed samples were obtained from the same precursor. Therefore, the loading
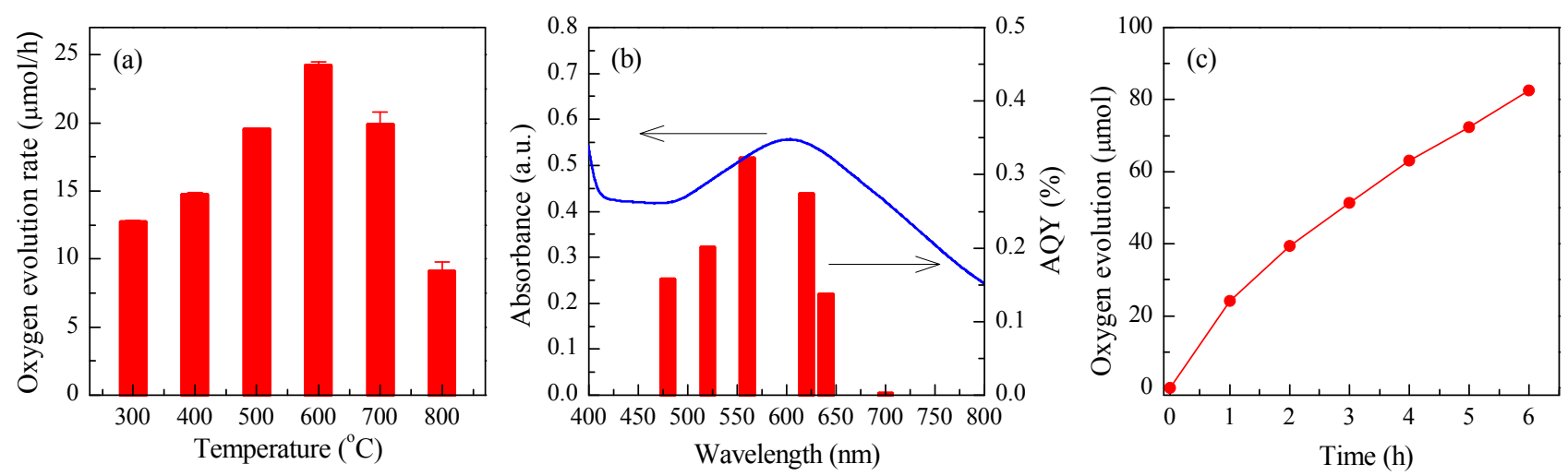

Fig. 1. (a) Photocatalytic water oxidation performance of $\mathrm{Au} / \mathrm{TiO}_{2}-T$ ( $T$ represents the post-calcination temperature) under illumination of visible light $(\lambda \geq 480 \mathrm{~nm})$. (b) Subtraction spectrum obtained from the spectra of $\mathrm{Au} / \mathrm{TiO}_{2}-600$ (blue line) and the $\mathrm{AQY}$ action spectrum of $\mathrm{Au} / \mathrm{TiO} \mathrm{O}_{2}-600 \mathrm{in}$ the water oxidation reaction (red histogram). (c) Time course of the produced $\mathrm{O}_{2}$ for $\mathrm{Au} / \mathrm{TiO}_{2}-600$. Experimental conditions: 50 mg photocatalyst, $100 \mathrm{~mL}$ of $5 \mathrm{mmol} / \mathrm{L} \mathrm{Fe}\left(\mathrm{NO}_{3}\right)_{3}$ aqueous solution, light source: Xe lamp (300 W) with Y48 bandpass filter $(\lambda \geq 480 \mathrm{~nm})$, illumination at $15{ }^{\circ} \mathrm{C}$ for $1 \mathrm{~h}$. The error bars show the standard deviations. 

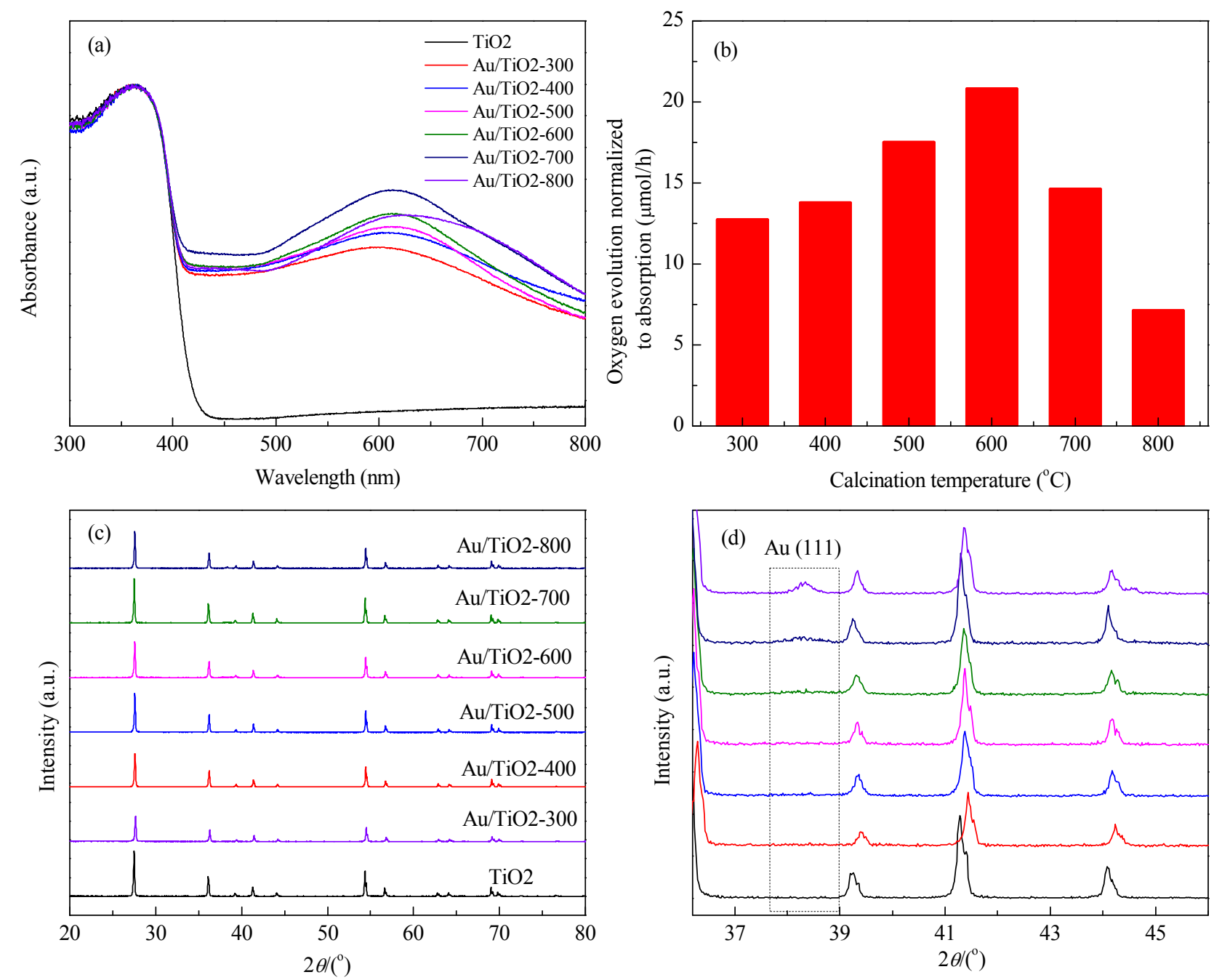

Fig. 2. (a) Diffuse-reflectance UV-vis spectra of bare $\mathrm{TiO}_{2}$ (rutile) and $\mathrm{Au} / \mathrm{TiO}_{2}-T$ photocatalysts. (b) The photocatalytic oxygen evolution activity normalized to the plasmon absorption from 480 to $800 \mathrm{~nm}$. (c) XRD patterns for bare $\mathrm{TiO}_{2}$ and $\mathrm{Au} / \mathrm{TiO}_{2}-\mathrm{T}$ photocatalyst powders. (d) Enlarged spectra of Fig. 2(c) to highlight the XRD patterns for Au signals at $38.1^{\circ}$.

amount of Au was consistent which was confirmed by the ICP results. Other explanations include the change of the $\mathrm{Au}$ size due to sintering, or an increase in the contact area of Au NPs and $\mathrm{TiO}_{2}$ since annealing is a common method of improving the interaction between $\mathrm{Au}$ and $\mathrm{TiO}_{2}$. Despite the changes in the absorption of the photocatalyst, the oxygen evolution activity is irrelevant to the absorption, where the intense plasmon absorption of $\mathrm{Au} / \mathrm{TiO}_{2}-700$ has a lower activity than $\mathrm{Au} / \mathrm{TiO}_{2}-600$. In particular, the water oxidation activity after light absorption normalization from 480 to $800 \mathrm{~nm}$ is similar to original (Fig. 2(b)), which further indicates that the light absorption properties are not the dominating factors in this system. Consequently, the $\mathrm{Au}$ size effect and the $\mathrm{Au}-\mathrm{TiO}_{2}$ interaction should be studied to understand the change in the water oxidation performance.

The surface properties of the $\mathrm{TiO}_{2}$ support will also influence the catalytic performance of $\mathrm{Au} / \mathrm{TiO}_{2}$ [33]. So the crystal structure of bare $\mathrm{TiO}_{2}$ and $\mathrm{Au} / \mathrm{TiO}_{2}-T$ were characterized by XRD, shown in Fig. 2(c). For the bare $\mathrm{TiO}_{2} \mathrm{NPs}$, all the diffraction peaks are ascribed to the tetragonal rutile $\mathrm{TiO}_{2}$. Once $\mathrm{Au}$ is loaded onto the $\mathrm{TiO}_{2}$ surface and calcined at various temperatures, there was no obvious change in the diffraction peaks, indicating that the crystal structure of $\mathrm{TiO}_{2}$ is similar for all of the samples, and that the titania phase differences among these samples were minimal. No diffraction of Au was observed when the photocatalysts were annealed below $600{ }^{\circ} \mathrm{C}$. A characteristic diffraction peak centered at $38.1^{\circ}$, corresponding to the (111) crystal plane of $\mathrm{Au}$, emerged only when the calcination temperature exceeded $600{ }^{\circ} \mathrm{C}$ and the peak became more pronounced as the temperature increased (Fig. 2(d)). It is wellknown that the growth and coalescence of Au NPs at elevated temperatures is inevitable. Hence the appearance of Au diffraction is a result of $\mathrm{Au}$ sintering and growth. These results exclude changes in the crystalline structure of $\mathrm{TiO}_{2}$ as a dominant factor for variation in the water oxidation activity.

\subsection{Au size effect in plasmon-induced water oxidation}

The size of the plasmonic metal is another essential factor influencing photocatalytic performance. Fig. 3 shows SEM im- 
ages of the $\mathrm{Au} / \mathrm{TiO}_{2}-\mathrm{T}$ series annealed at temperatures between 300 and $800{ }^{\circ} \mathrm{C}$. Well-dispersed Au NPs were uniformly loaded on the $\mathrm{TiO}_{2}$ surface in all six samples. The size of the resulting $\mathrm{Au}$ NPs was determined to be $3.17,3.26,4.26,7.0,14.1$, and $42.3 \mathrm{~nm}$ for $\mathrm{Au} / \mathrm{TiO}_{2}-300,400,500,600,700$, and 800 , respectively. The Au NPs become larger as the annealing temperature increases, and their dispersion become sparse due to sintering. The rate at which the Au NPs increase in size is much slower when the calcination temperature is below $600^{\circ} \mathrm{C}$, in particular the diameters of $\mathrm{Au} / \mathrm{TiO}_{2}-300$ and $\mathrm{Au} / \mathrm{TiO}_{2}-400$ are almost the same (approximately $3.2 \mathrm{~nm}$ ). In contrast, the Au particle size increases much more rapidly when the annealing temperature is greater than $700{ }^{\circ} \mathrm{C}$ and the $\mathrm{Au}$ grows into quite large particles, approximately $42 \mathrm{~nm}$, when the annealing temperature is $800{ }^{\circ} \mathrm{C}$. The growth of the $\mathrm{Au}$ particles through annealing at elevated temperatures is due to their low Tammann tempera- ture and high surface energy [43]. The TEM results show that the Au particle sizes are consistent with the UV-visible absorption and XRD results mentioned above.

When the Au particle size and corresponding water oxidation were compared, an interesting phenomenon was observed, as shown in Fig. 4. The inflection point for the size of the $\mathrm{Au}$ particles is at approximately $500-600{ }^{\circ} \mathrm{C}$, at which point the photocatalyst has the highest water oxidation activity. Therefore, Fig. 4 can be divided into two regions (as denoted with the dotted line): one below $600{ }^{\circ} \mathrm{C}$, where the size of the $\mathrm{Au}$ NPs changes gradually and the water oxidation activities increase; the other above $600{ }^{\circ} \mathrm{C}$, where the size of the Au NPs increases sharply while the water oxidation activities decrease sharply. This discrepancy between the Au size variations and water oxidation change show that another factor, besides metal size, must also play an important role in plasmon-induced wa-
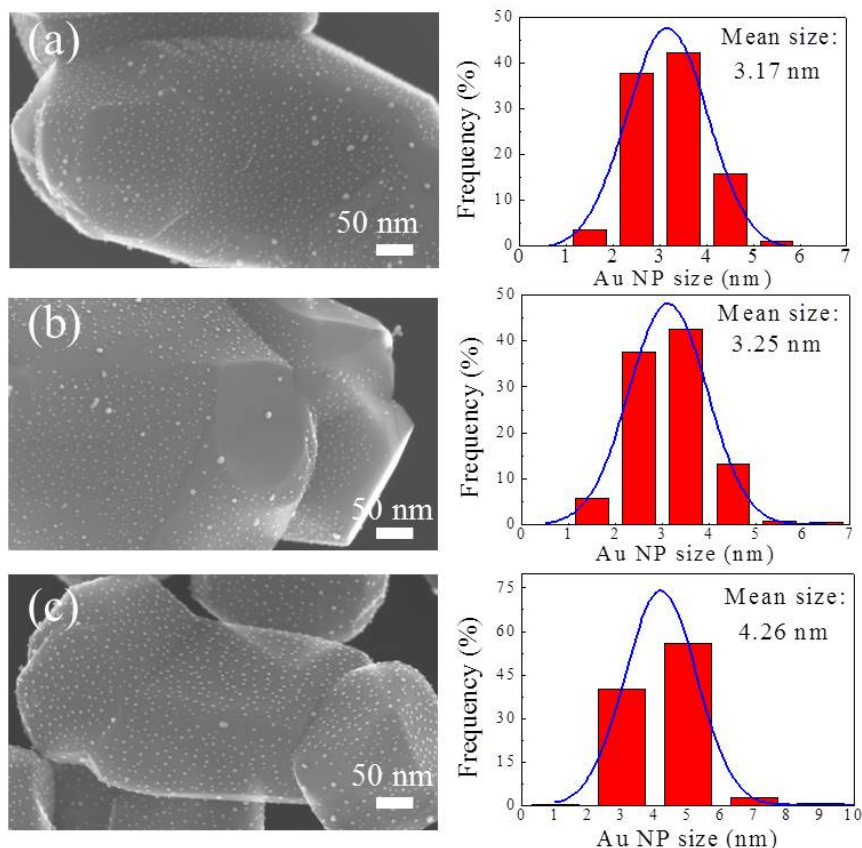
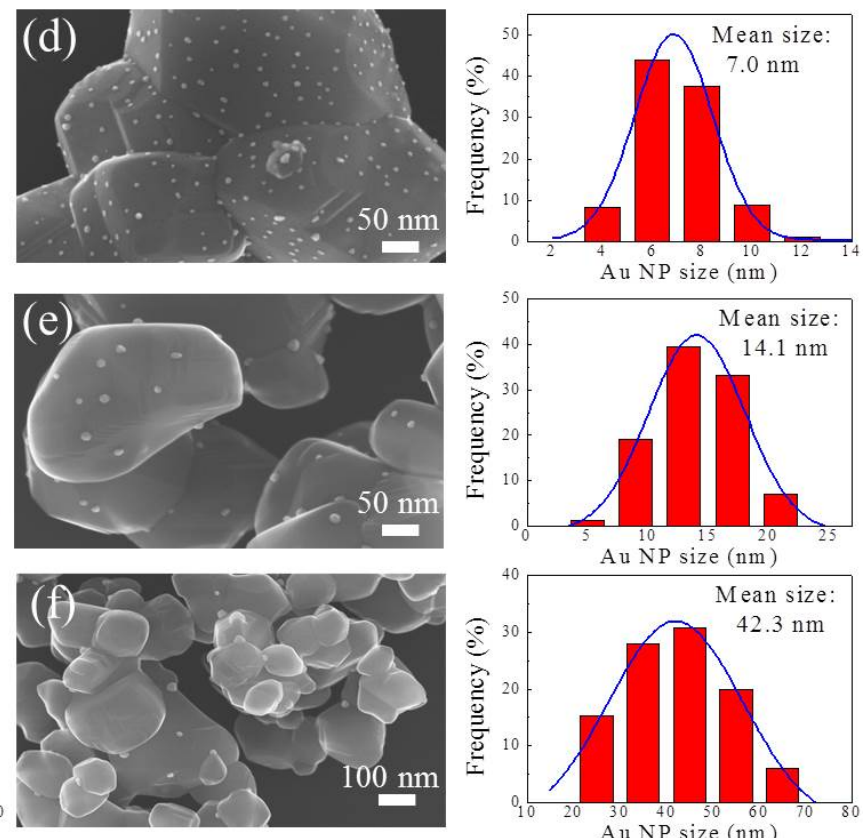

Fig. 3. $\mathrm{SEM}$ micrographs of $\mathrm{Au} / \mathrm{TiO}_{2}-\mathrm{T}$. (a) $\mathrm{Au} / \mathrm{TiO}_{2}-300$, (b) $\mathrm{Au} / \mathrm{TiO}_{2}-400$, (c) $\mathrm{Au} / \mathrm{TiO}_{2}-500$, (d) $\mathrm{Au} / \mathrm{TiO}_{2}-600$, (e) $\mathrm{Au} / \mathrm{TiO}_{2}-700$, (f) $\mathrm{Au} / \mathrm{TiO}_{2}-800$. The right-hand panels in each figure represent the size distribution according to the SEM images.
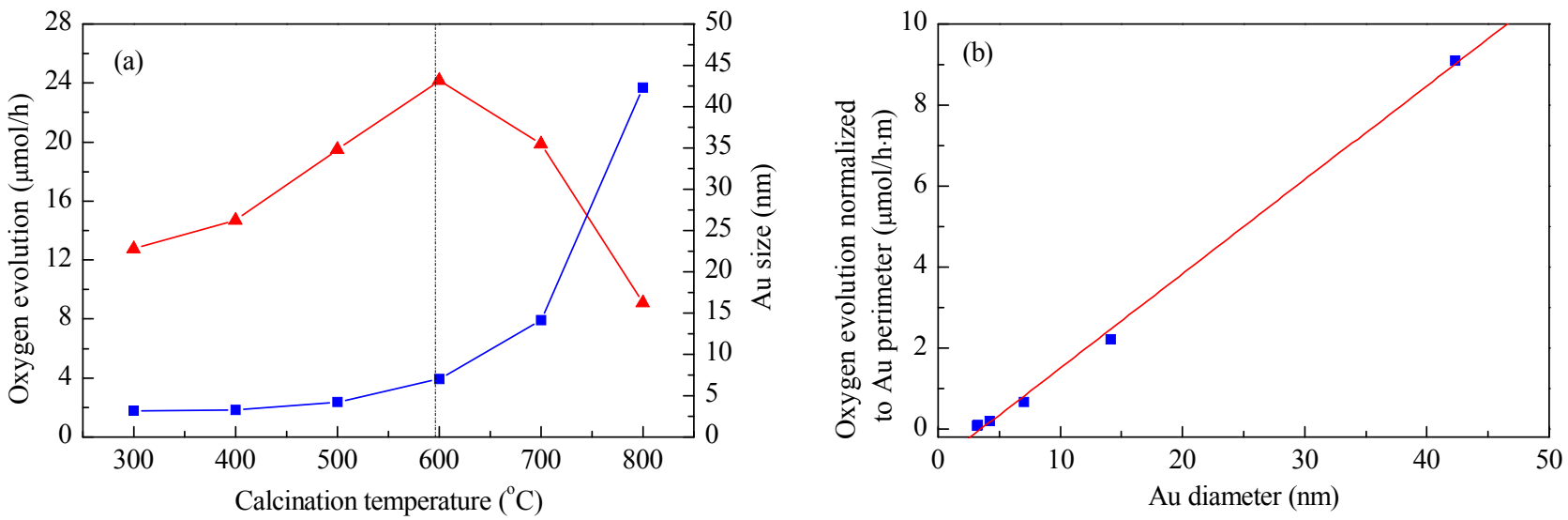

Fig. 4. (a) The relationship between photocatalytic water oxidation activity and the size of Au NPs for different calcination temperatures. (b) The relationship between photocatalytic water oxidation after interface perimeters normalized and $\mathrm{Au} \mathrm{NP}$ size. The normalization of the $\mathrm{Au}^{-\mathrm{TiO}} \mathrm{O}_{2}$ perimeter is based on the hemisphere model where uniform dispersed hemispherical Au NPs are loaded onto a flat $\mathrm{TiO}_{2}$ surface. 
ter oxidation, especially at lower temperatures.

\section{4. $\mathrm{Au}-\mathrm{TiO}_{2}$ interaction effect in plasmon-induced water oxidation}

It is well known that annealing at an elevated temperature can enhance the contact between metal NPs and their support via strong interfacial bonding, since metal NPs rearrange their atomic structures and form strong interactions with the support at high temperatures [44]. In this case, the $\mathrm{Au}^{-\mathrm{TiO}_{2}}$ interaction may also affect the plasmonic photocatalytic performance by altering the charge separation efficiency and surface reaction. Specifically, the water oxidation performance was normalized according to the perimeter length of the $\mathrm{Au}-\mathrm{TiO}_{2}$ interface (Fig. 4(b)). We modeled uniformly dispersed hemispherical $\mathrm{Au}$ NPs on the flat $\mathrm{TiO}_{2}$ surface based on the SEM images (Fig. 3). As a consequence, the perimeter length is inversely proportional to the square of the diameter (see the Supporting Information). After normalization, the water oxidation was proportional to the Au NP size. Considering that the perimeter region is the primary reaction site for water oxidation [33], the linear relation is mainly due to the enhancement of the $\mathrm{Au}-\mathrm{TiO}_{2}$ interactions.

Next, XPS was conducted to characterize the metal-support interaction (Fig. 5). In the Au $4 f$ XPS spectra, the binding energy of $\mathrm{Au} 4 f_{7 / 2}$ was determined to be $83.5-83.6 \mathrm{eV}$ for $\mathrm{Au} / \mathrm{TiO}_{2}-300$ and $\mathrm{Au} / \mathrm{TiO}_{2}-400$, which is in good agreement with data available in the literature for metallic gold [45]. After calcination at higher temperatures $\left(\geq 500{ }^{\circ} \mathrm{C}\right)$, an obvious shift of binding energy to lower energies was observed and the binding energy decreased with increasing temperature (Fig. 5(c)), indicating that the $\mathrm{Au}$ NPs supported on $\mathrm{TiO}_{2}$ had become electron-rich [46]. This result is in accord with the Schottky barrier theory, in which $\mathrm{TiO}_{2}$ has a small work function and gives electrons to the $\mathrm{Au}$ NPs with a higher work function. According to previous reports, the electron transfer from the support to the metal NPs is a strong indicator of the improved interfacial contact between the $\mathrm{Au}$ NPs and $\mathrm{TiO}_{2}$. In the $\mathrm{Ti} 2 p$ spectra, no difference in the titanium species was discovered among the six samples, indicating their similar electronic properties. The improved interfacial contact between the $\mathrm{Au}$ and $\mathrm{TiO}_{2}$ was further verified by TEM characterization (Fig. 6). The morphology of the $\mathrm{Au}$ NPs changed from spherical in $\mathrm{Au} / \mathrm{TiO}_{2}-400$ to ellipsoid in $\mathrm{Au} / \mathrm{TiO}_{2}-600$ and $\mathrm{Au} / \mathrm{TiO}_{2}-700$. What is more, the $\mathrm{Au}$ NPs were
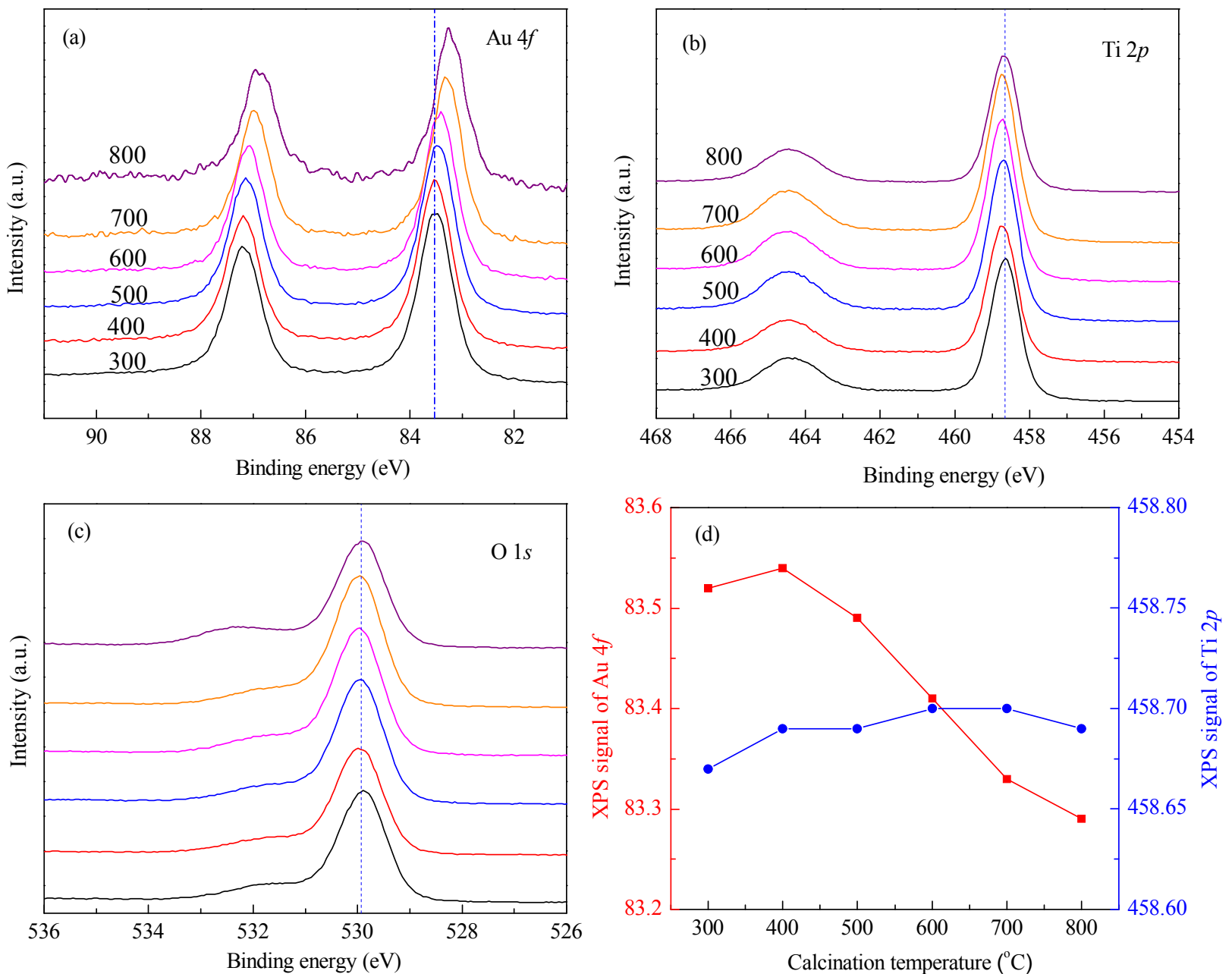

Fig. 5. XPS spectra for $\mathrm{Au} / \mathrm{TiO}_{2}-T$ photocatalysts. (a) $\mathrm{Au} 4 f$, (b) $\mathrm{Ti} 2 p$, (c) $01 s$, (d) The binding energy shifts of Au $4 f$ and $\mathrm{Ti} 2 p$ related to the calcination temperature. 

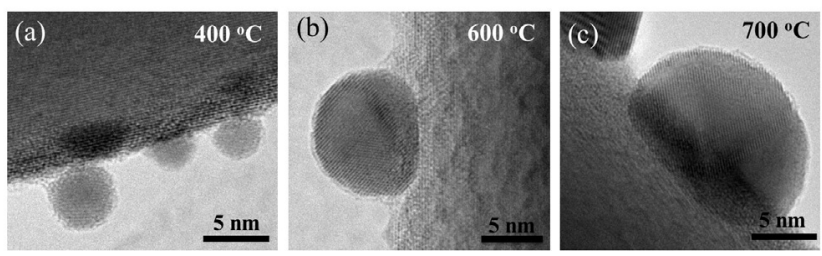

Fig. 6. HRTEM micrographs of $\mathrm{Au} / \mathrm{TiO}_{2}-400$ (a), $\mathrm{Au} / \mathrm{TiO}_{2}-600$ (b), and $\mathrm{Au} / \mathrm{TiO}_{2}-700$ (c).

partly embedded into the $\mathrm{TiO}_{2}$ surface when the temperature was raised. Note that the growth of the Au particles was also observed after annealing at elevated temperatures. Thus, the electronic interaction between the $\mathrm{Au}$ NPs and $\mathrm{TiO}_{2}$ was enhanced by increased annealing engineering, although the Au NP size also increased.

Considering the plasmon-induced water oxidation performance shown in Fig. 4, the enhanced activity of the left-hand region, below $600{ }^{\circ} \mathrm{C}$, is mainly due to the improvement in the $\mathrm{Au}-\mathrm{TiO}_{2}$ interfacial interaction. To further demonstrate this deduction, we designed another series of photocatalysts using the photodeposition-annealing method. Relatively large $\mathrm{Au}$ particles (30-60 nm) were obtained after photodeposition (PD) under illumination of UV light. Importantly, the size of these $\mathrm{Au}$ NPs remained approximately the same even after treatment at $600{ }^{\circ} \mathrm{C}$ (Fig. 7(a) and (b)). However, the water oxidation activity of these samples changed with the annealed temperature, where photocatalysts treated at higher temperatures had higher activity (Fig. 7(c)). This result clearly indicates that the $\mathrm{Au}-\mathrm{TiO}_{2}$ interaction has a vital role in plasmon-induced water oxidation, as the interfacial region between the $\mathrm{Au}$ and $\mathrm{TiO}_{2}$ has previously been demonstrated to be a reactive site for water oxidation.
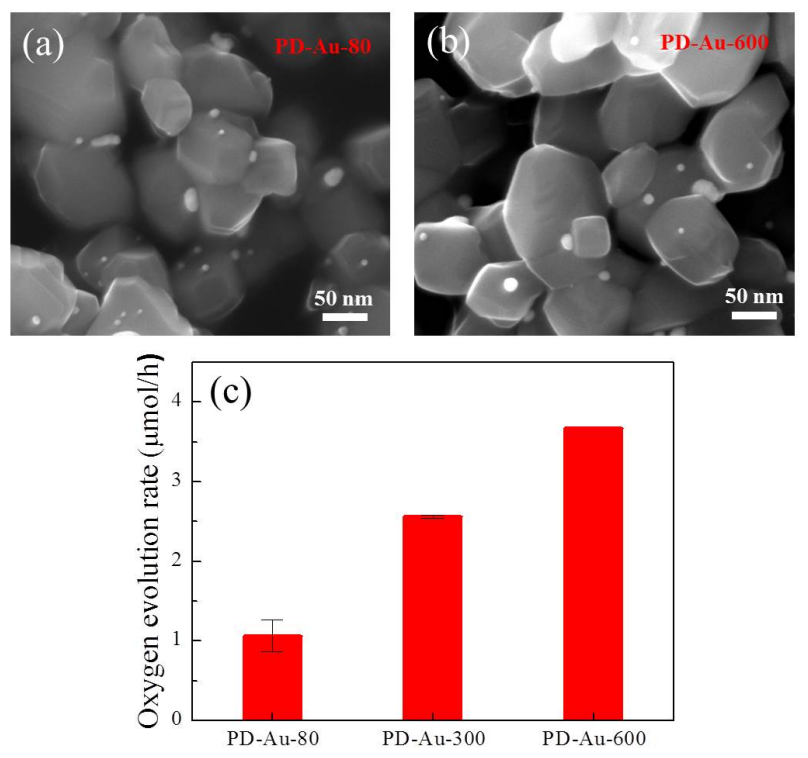

Fig. 7. SEM micrographs of $\mathrm{PD}-\mathrm{Au} / \mathrm{TiO}_{2}$ calcined at $80{ }^{\circ} \mathrm{C}(\mathrm{a})$ and $600{ }^{\circ} \mathrm{C}$ (b). The loading of $\mathrm{Au}$ on $\mathrm{TiO}_{2}$ prepared by the photodeposition method under UV light illumination. (c) The corresponding water oxidation performance of $\mathrm{PD}-\mathrm{Au}-\mathrm{T}$. Experimental conditions: $50 \mathrm{mg}$ photocatalyst $100 \mathrm{~mL}$ of $5 \mathrm{mmol} / \mathrm{L} \mathrm{Fe}\left(\mathrm{NO}_{3}\right)_{3}$ aqueous solution, light source: Xe lamp $(300 \mathrm{~W})$ with Y48 bandpass filter, illumination at $15^{\circ} \mathrm{C}$ for $1 \mathrm{~h}$. The error bars show the standard deviations.
These results indicate that the optimized water oxidation performance is the result of cooperative synergy between the $\mathrm{Au} \mathrm{NP}$ size and the $\mathrm{Au}-\mathrm{TiO}_{2}$ interaction. As a typical protocol of plasmonic photocatalyst, $\mathrm{Au} / \mathrm{TiO}_{2}$ is usually used to expand the absorption of $\mathrm{TiO}_{2}$ due to the hot electron transfer from $\mathrm{Au}$ NPs to the semiconductor. The size of the Au NPs and the interaction between $\mathrm{Au}$ and $\mathrm{TiO}_{2}$ are two crucial parameters responsible for the photocatalytic activity, which will affect the energy distribution of the plasmon-induced charges and the efficiency of the charge transfer, respectively. According to the theoretical results, the generation rate of hot-energy electron and holes, which can be used for photocatalysis, increases as the size of the metal NPs decreases [47]. In addition, since the interfacial region between $\mathrm{Au}$ and $\mathrm{TiO}_{2}$ has been shown to be the water oxidation reaction site [33], both size the and interaction will also impact the surface reaction. The fact that best photocatalyst out of the samples was $\mathrm{Au} / \mathrm{TiO}_{2}-600$ is ascribed to the moderate Au NP size, which leads to sufficient high-energy hot holes and active sites for water oxidation. Moreover, $\mathrm{Au} / \mathrm{TiO}_{2}-600$ is treated at high temperature $\left(600{ }^{\circ} \mathrm{C}\right)$ which introduces a strong enough metal-semiconductor interaction for water oxidation and charge transfer. Therefore, the intimate integration of suitably sized $\mathrm{Au} \mathrm{NPs}$ on $\mathrm{TiO}_{2}$ results in the distinctly boosted performance for plasmonic photocatalysis.

\section{Conclusions}

$\mathrm{Au} / \mathrm{TiO}_{2}$ prepared using the DP method exhibited optical absorption in the visible light region due to the SPR of Au NPs and $\mathrm{Au} / \mathrm{TiO}_{2}$ was shown to be a potential water oxidation photocatalyst under irradiation with visible light. More importantly, both the size of the Au NPs and the interaction between $\mathrm{Au}$ and $\mathrm{TiO}_{2}$ could be controlled by post-calcination of $\mathrm{Au} / \mathrm{TiO}_{2}$. As the calcination temperature was increased, both the size of the $\mathrm{Au} \mathrm{NPs}$ and the $\mathrm{Au}-\mathrm{TiO}_{2}$ interaction gradually increased, whereas the crystallization and size of $\mathrm{TiO}_{2}$ remained constant. A volcanic curve for water oxidation activity was presented relative to the calcination temperature and the optimized performance for the photocatalyst was achieved after post-calcination at $600{ }^{\circ} \mathrm{C}$. The volcanic curve is a result of the compensating effects of the $\mathrm{Au} \mathrm{NP}$ size and the $\mathrm{Au}-\mathrm{TiO}_{2}$ interaction, in which moderate Au NP size with a strong metal-support interaction gives the highest water oxidation performance.

\section{References}

[1] J. R. Ran, J. Zhang, J. G. Yu, M. Jaroniec, S. Z. Qiao, Chem. Soc. Rev., 2014, 43, 7787-7812.

[2] H. Du, Y. N. Liu, C. C. Shen, A. W. Xu, Chin. J. Catal., 2017, 38, 1295-1306.

[3] R. G. Li, Chin. J. Catal., 2017, 38, 5-12.

[4] W. Ye, R. Long, H. Huang, Y. J. Xiong, J. Mater. Chem. C, 2017, 5, 1008-1021.

[5] S. Linic, P. Christopher, D. B. Ingram, Nat. Mater., 2011, 10, 911-921.

[6] C. Han, Q. Quan, H. M. Chen, Y.G. Sun, Y. J. Xu, Small, 2017, 13, 1602947. 
[7] G.V. Hartland, Chem. Rev., 2011, 111, 3858-3887.

[8] M. L. Brongersma, N. J. Halas, P. Nordlander, Nat. Nanotechnol., 2015, 10, 25-34.

[9] K. L. Kelly, E. Coronado, L. L. Zhao, G. C. Schatz, J. Phys. Chem. B, 2003, 107, 668-677.

[10] R. B. Jiang, B. X. Li, C. H. Fang, J. F. Wang, Adv. Mater., 2014, 26, 5274-5309.

[11] P. Zhang, T. Wang, J. L. Gong, Adv. Mater., 2015, 27, 5328-5342.

[12] M. Valenti, M. P. Jonsson, G. Biskos, A. Schmidt-Ott, W. A. Smith, J. Mater. Chem. A, 2016, 4, 17891-17912.

[13] X. Yang, W. Q. Liu, H. Z. Chen, Sci. China Chem., 2015, 58, 210-220.

[14] W. J. Ong, L. K. Putri, L. L. Tan, S. P. Chai, S. T. Yong, Appl. Catal. B, 2016, 180, 530-543.

[15] C. W. Moon, S. Y. Lee, W. Sohn, D. M. Andoshe, D. H. Kim, K. Hong, H. W. Jang, Part. Part. Syst. Charact., 2017, 34, 1600340.

[16] Y. Chen, X. Xin, N. Zhang, Y. J. Xu, Part. Part. Syst. Charact., 2017, $34,1600357$.

[17] Z. H. Xu, M. G. Kibria, B. AlOtaibi, P. N. Duchesne, L. V. Besteiro, Y. Gao, Q. Z. Zhang, Z. T. Mi, P. Zhang, A. O. Govorov, L. Q. Mai, M. Chaker, D. L. Ma, Appl. Catal. B, 2018, 221, 77-85.

[18] P. Christopher, M. Moskovits, Annu. Rev. Phys. Chem., 2017, 68, 379-398.

[19] T. Tatsuma, H. Nishi, T. Ishida, Chem. Sci., 2017, 8, 3325-3337.

[20] C. C. Jia, X. X. Li, N. Xin, Y. Gong, J. X. Guan, L. A. Meng, S. Meng, X. F. Guo, Adv. Energy Mater., 2016, 6, 1600431.

[21] C. M. Ding, J. Y. Shi, Z. L. Wang, C. Li, ACS Catal., 2017, 7, 675-688.

[22] J. H. Yang, D. G. Wang, H. X. Han, C. Li, Acc. Chem. Res., 2013, 46, 1900-1909.

[23] L. Yang, D. Zhong, J. Y. Zhang, Z. P. Yan, S. F. Ge, P. W. Du, J. Jiang, D. Sun, X. J. Wu, Z. Y. Fan, S. A. Dayeh, B. Xiang, ACS Nano, 2014, 8, 6979-6985.
[24] S. W. Cao, Y. Li, B. C. Zhu, M. Jaroniec, J. G. Yu, J. Catal., 2017, 349, 208-217.

[25] V. Subramanian, E. E. Wolf, P. V. Kamat, J. Am. Chem. Soc., 2004 126, 4943-4950.

[26] W. P. Gao, Z. D. Hood, M. F. Chi, Acc. Chem. Res., 2017, 50, 787-795.

[27] M. Haruta, Chin. J. Catal., 2016, 37, 1441-1442.

[28] X. Y. Liu, A. Q. Wang, T. Zhang, C. Y. Mou, Nano Today, 2013, 8, 403-416.

[29] K. J. Sun, Chin. J. Catal., 2016, 37, 1608-1618.

[30] Z. F. Bian, T. Tachikawa, P. Zhang, M. Fujitsuka, T. Majima, J. Am. Chem. Soc., 2014, 136, 458-465.

[31] M. Dilla, A. Pougin, J. Strunk, J. Energy Chem., 2017, 26, 277-283.

[32] K. Qian, B. C. Sweeny, A. C. Johnston-Peck, W. X. Niu, J. O. Graham, J. S. DuChene, J. J. Qiu, Y. C. Wang, M. H. Engelhard, D. Su, E. A. Stach, W. D. Wei, J. Am. Chem. Soc., 2014, 136, 9842-9845.

[33] S. Y. Wang, Y. Y. Gao, S. Miao, T. F. Liu, L. C. Mu, R. G. Li, F. T. Fan, C. Li, J. Am. Chem. Soc., 2017, 139, 11771-11778.

[34] X. N. Wang, R. Long, D. Liu, D. Yang, C. M. Wang, Y. J. Xiong, Nano Energy, 2016, 24, 87-93.

[35] B. H. Wu, D. Y. Liu, S. Mubeen, T. T. Chuong, M. Moskovits, G. D. Stucky, J. Am. Chem. Soc., 2016, 138, 1114-1117.

[36] S. Y. Wang, Y. Y. Gao, Y. Qi, A. L. Li, F. T. Fan, C. Li, J. Catal., 2017 $354,250-257$.

[37] S. Mubeen, J. Lee, N. Singh, S. Kramer, G. D. Stucky, M. Moskovits, Nat. Nanotechnol., 2013, 8, 247-251.

[38] M. Teranishi, M. Wada, S. Naya, H. Tada, ChemPhysChem, 2016, 17, 2813-2817.

[39] J. M. Zhang, X. Jin, P. I. Morales-Guzman, X. Yu, H. Liu, H. Zhang, L. Razzari, J. P. Claverie, ACS Nano, 2016, 10, 4496-4503.

[40] K. Kimura, S. Naya, Y. Jin-nouchi, H. Tada, J. Phys. Chem. C, 2012 116, 7111-7117.

\section{Graphical Abstract}

Chin. J. Catal., 2018, 39: 1219-1227 doi: 10.1016/S1872-2067(18)63094-3

Effects of Au nanoparticle size and metal-support interaction on plasmon-induced photocatalytic water oxidation

Shengyang Wang, Bin Zeng, Can Li *

Dalian Institute of Chemical Physics, Chinese Academy of Sciences; University of Chinese Academy of Sciences
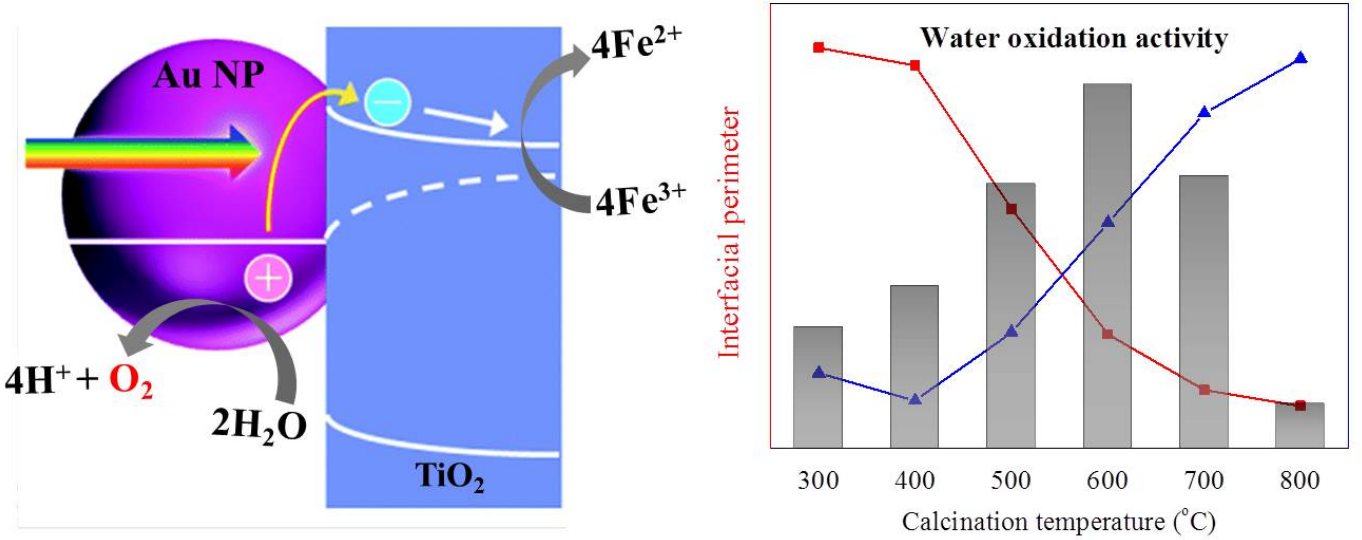

We elucidated the influence of $\mathrm{Au}$ nanoparticle size and $\mathrm{Au}-\mathrm{TiO}_{2}$ interaction in plasmon-induced photocatalytic water oxidation on a $\mathrm{Au} / \mathrm{TiO}_{2}$ photocatalyst. 
[41] A. Tanaka, S. Sakaguchi, K. Hashimoto, H. Kominami, ACS Catal., 2013, 3, 79-85.

[42] M. M. Maitani, T. Yamada, H. Mashiko, K. Yoshimatsu, T. Shim, A. Ohtomo, Y. Wada, ACS Appl. Mater. Interfaces, 2017, 9, 10349-10354.

[43] W. C. Zhan, Q. He, X. F. Liu, Y. L. Guo, Y. Q. Wang, L. Wang, Y. Guo, A. Y. Borisevich, J. S. Zhang, G. Z. Lu, S. Dai, J. Am. Chem. Soc., 2016, 138, 16130-16139.

[44] D. Matthey, J. G. Wang, S. Wendt, J. Matthiesen, R. Schaub, E.
Laegsgaard, B. Hammer, F. Besenbacher, Science, 2007, 315, 1692-1696.

[45] L. Wang, H. Wang, A. E. Rice, W. Zhang, X. K. Li, M. S. Chen, X. J. Meng, J. P. Lewis, F. S. Xiao, J. Phys. Chem. Lett., 2015, 6, 2345-2349.

[46] S. Tsubota, T. Nakamura, K. Tanaka, M. Haruta, Catal. Lett., 1998, 56, 131-135.

[47] G. V. Hartland, L. V. Besteiro, P. Johns, A. O. Govorov, ACS Energy Lett., 2017, 2, 1641-1653.

\title{
金纳米粒子的尺寸以及金-二氧化钛相互作用对表面等离激元光催化产氧的影响
}

\author{
王升扬 ${ }^{\mathrm{a}, \mathrm{b}}$, 曾 斌 ${ }^{\mathrm{a}, \mathrm{b}}$, 李 灿 ${ }^{\mathrm{a},{ }^{*}}$ \\ ${ }^{\mathrm{a}}$ 中国科学院大连化学物理研究所, 催化基础国家重点实验室, 洁净能源国家实验室(筹), \\ 能源材料化学协同创新中心, 辽宁大连 116023 \\ 占国科学院大学, 北京 100049
}

\begin{abstract}
摘要: 表面等离激元共振效应具有独特的光-物质相互作用的性质, 因而近年来被广泛的应用到太阳能转化科学领域. 通 过调变金属的性质（例如组分、尺寸、形貌等）可以方便地在整个太阳能光谱范围内调节其等离子共振吸收性质, 从而有 效地增加光催化剂的捕光效率. 尽管如此, 等离激元光催化目前的能量转化效率仍处于很低的水平, 主要是由于光催化剂 中的电荷分离以及利用效率很低. 理论上可以通过控制优化金属纳米粒子的尺寸以及金属-半导体的相互作用来促进电荷 分离及利用效率, 从而提高光催化剂的活性. 然而, 关于金属纳米粒子的尺寸以及金属-半导体的相互作用在表面等离激元 光催化剂中的具体作用还亟待详细研究. 本文以金/二氧化钛作为典型的表面等离激元光催化剂, 通过简便的焙烧后处理 可同时实现金粒子尺寸和金-氧化钛界面相互作用的调控. 我们发现, 催化剂的可见光产氧活性随着焙烧温度呈现火山型 关系, 其中 $600{ }^{\circ} \mathrm{C}$ 处理的样品表现出最高的活性, 在 $560 \mathrm{~nm}$ 出的表观量子效率为 $0.3 \%$, 接近甚至超过文献报道的同类结果. 随后通过X射线衍射、扫描电镜、光电子能谱、紫外可见光谱等表征手段系统地研究了炦烧温度对于金粒子尺寸和金-氧 化钛相互作用的影响. 从结果表明, 通过不同温度焙烧并未改变二氧化钛自身的性质, 且随着温度的升高, 金尺寸在 $600{ }^{\circ} \mathrm{C}$ 之前变化较小, 随后突然快速长大. 在排除了不同样品的吸光性能的差异后发现, 产氧活性随着 $\mathrm{Au}$ 尺寸长大而减少. 从光 电子能谱的结果发现, 金-二氧化钛的界面相互作用随焙烧温度升高而逐步增强. 进一步地, 通过界面周长的归一化活性得 出界面相互作用与产氧活性呈现近似线性关系. 最后, 通过对光沉积Au样品进行不同温度的㷽烧发现大尺寸 $\mathrm{Au}$ 的粒径不 随㷽烧温度变化, 而此时的产氧活性却随焙烧温度增加而增加, 这进一步验证了界面相互作用对光催化水氧化的促进作 用. 综合以上结果可知, 最终的等离激元诱导的可见光产氧活性是由尺寸与界面相互作用共同影响的结果, 尺寸和界面相 互作用的变化会共同影响热电子转移效率和表面反应效率, 从而改变整体的光催化产氧效率.
\end{abstract}

关键词: 金/二氧化钛; 水氧化; 表面等离激元光催化; 尺寸效应; 金属-半导体相互作用

收稿日期: 2017-12-27. 接受日期: 2018-04-29. 出版日期: 2018-07-05.

*通讯联系人. 电话: (0411)84379070; 传真: (0411)84694447; 电子邮箱: canli@dicp.ac.cn

基金来源：国家自然科学基金(21633010); 国家重点基础研究发展计划(973计划, 2014CB239400); 中国科学院战略先导专项 (XDB01020300).

本文的电子版全文由Elsevier出版社在ScienceDirect上出版(http://www.sciencedirect.com/science/journal/18722067). 